\title{
Mariposa traicionera
}

\section{Treacherous Butterfly}

\author{
Francisco Medina Romero ${ }^{1}$ Juan A. Hernández Ponce ${ }^{2}$ Ester Morcillo García ${ }^{3}$
}

${ }^{1}$ Servicio de Medicina Nuclear, Complejo Hospitalario Universitario de Canarias (CHUC), La Laguna, Santa Cruz de Tenerife, España

${ }^{2}$ Servicio de Radiología, Complejo Hospitalario Universitario de Canarias (CHUC), La Laguna, Santa Cruz de Tenerife, España

${ }^{3}$ Servicio de Pediatría, Complejo Hospitalario Universitario de Canarias (CHUC), La Laguna, Santa Cruz de Tenerife, España

Rev Argent Radiol 2022;85(Suppl S1):S26-S27.

Presentamos el caso de un recién nacido pretérmino de 28 semanas, que nació con distress respiratorio por enfermedad de la membrana hialina.

En su segundo día de vida, y dado el cuadro anterior, se decidió realizar una radiografía simple de tórax, en la que se observó un neumotórax bilateral (-Fig. 1).

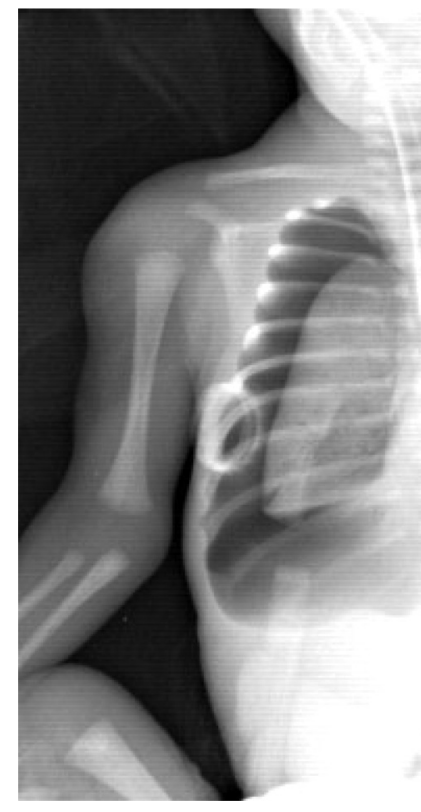

Fig. 1 Radiografía de tórax.

\section{received}

July 1,2019

accepted

October 9, 2019

published online

January 9, 2020
Address for correspondence Francisco Medina Romero, Servicio de Medicina Nuclear, Complejo Hospitalario Universitario de Canarias (CHUC), Carretera de Ofra, s/n, San Cristóbal de La Laguna, Santa Cruz de Tenerife, España (e-mail: drfranciscomedina@gmail.com).
La imagen formada por la presencia de aire rodeando la totalidad de ambos pulmones en esta prueba y la gravedad de la situación, nos recuerdan a la famosa "Mariposa traicionera" (-Fig.2) de la canción de la banda de música mexicana Maná.

\section{Conflictos de intereses}

Los autores declaran que no existen conflictos de intereses.

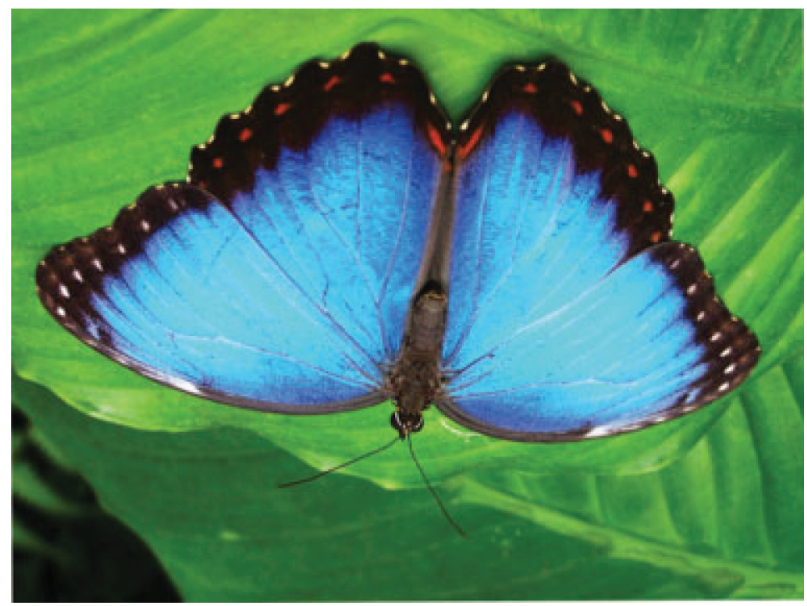

Fig. 2 Imagen de una mariposa.

(c) 2020. Asociación Civil Sociedad Argentina de Radiología and Federacion Argentina de Asociaciones de Radiología, Diagnóstico por Imágenes y Terapia Radiante. All rights reserved.

This is an open access article published by Thieme under the terms of the Creative Commons Attribution-NonDerivative-NonCommercial-License, permitting copying and reproduction so long as the original work is given appropriate credit. Contents may not be used for commercial purposes, or adapted, remixed, transformed or built upon. (https://creativecommons.org/ licenses/by-nc-nd/4.0/)

Thieme Revinter Publicações Ltda., Rua do Matoso 170, Rio de Janeiro, RJ, CEP 20270-135, Brazil 


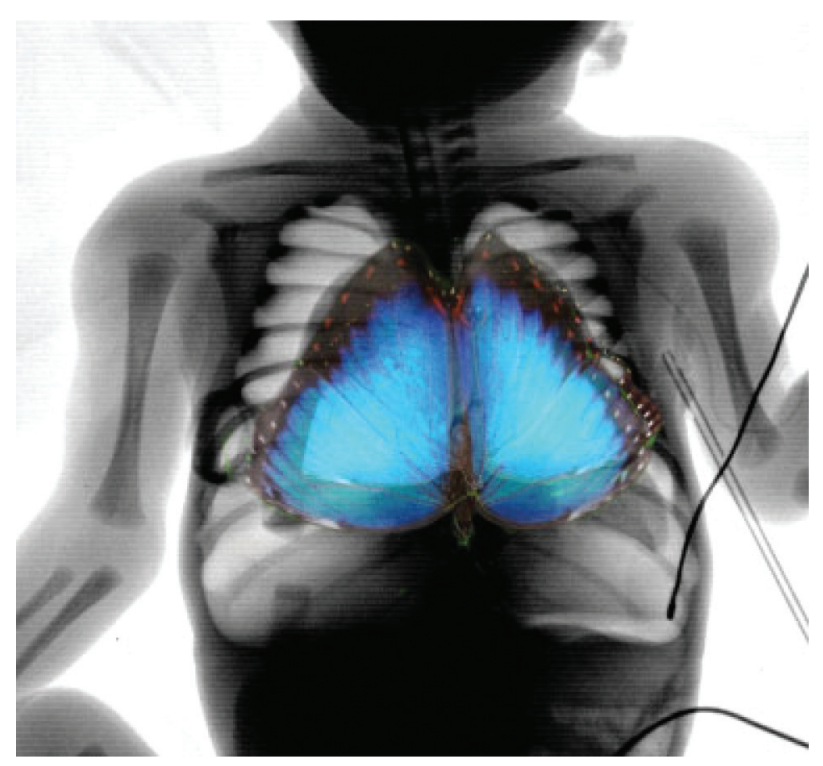

Fig. 3 Imagen fusionada. 